\title{
https://doi.org/10.48009/1_iis_2005_121-126 \\ PEDAGOGICAL IMPLICATIONS OF TECHNOLOGY: TOWARD A MORE CRITICAL STANCE OF INSTRUCTIONAL TECHNOLOGY
}

\author{
Dr. Dacia Charlesworth, Robert Morris University, charlesworth@rmu.edu \\ Dr. William J. McKinney, Slippery Rock University, william.mckinney@sru.edu
}

\begin{abstract}
This essay argues that technology is not valueless; that is, technology comes equipped with its own set of values. Thus, before we continue to implement instructional technology (IT), we must consider the consequences of those values for instructors as well as students. Moreover, one of the motivations behind using IT is that such techniques transcend the barriers of more traditional Socratic techniques. We argue that once we examine the most compelling arguments for IT (i.e., that it encourages discovery-based, constructive learning styles), it emerges as more Socratic than it would first appear. We maintain that IT has the potential to benefit pedagogy, but caution instructors to think critically about IT, and its implicit ideology, as well as their role of educator rather than trainer.
\end{abstract}

Keywords: instructional technology, pedagogy, technological minimalism, technological values

\section{INTRODUCTION}

For many instructors, one motivation for using instructional technology (IT) is that such techniques transcend the barriers of more traditional pedagogic techniques. Terms such as "interactivity" and "multimedia" dominate the educational technology literature. We also hear terms such as "constructivist" and "discovery-based learning." Quite simply, the literature states that computers will assist us in breaking down the walls between instructor and learner, creating an environment where students discover new insights and construct knowledge, as opposed to what is perceived as an outdated system where an omniscient professorial mind imparts knowledge to a passive student body that takes notes and repeats the information on objective examinations. This would seem to place IT squarely within the camp of Paulo Freire and other educational reformers, who argue that students are best thought of as active subjects instead of passive objects - constructors of knowledge rather than receptacles of it [6].

While the constructivist classroom, with its emphasis upon dialogue between instructor and student, appears to be an unique concept, we find that we have only returned full circle to a model of education that is, at least partly, dialectic. We are not speaking of an educational structure that is hierarchical and elitist in the Platonic sense, but rather of a model that is based upon questions directed to the student in order to access a pre-existing body of knowledge. If we are truly to view education as an exercise in knowledge construction, then we must fully appreciate the logic of contextuality, and that logic is an interrogative logic - a logic of questions and answers where questions are directed to a knowledge base and knowledge is constructed by exploring both the logical consequences of that base (in a rationalistic sense) and the inadequacies of that base (i.e., the locus of newly constructed knowledge). Since any computerized teaching technique necessarily accesses pre-existing knowledge (i.e., the computer's programming), IT is inherently interrogative, dialectic, and contextual. The purpose 
of this essay, then, is to examine the consequences of utilizing IT. We begin by offering a context in which to view IT. Second, we discuss the advantages of using IT. Next, we offer some considerations for those choosing to use IT. Finally, we conclude by offering recommendations for becoming better educators who use IT.

\section{The Context of Instructional Technology}

Instructional Technology's contextuality is best understood in a Heidegerrian framework. According to Heidegger, technology "enframes," and thus creates its own context [8]. Once committed to a particular technology, one commits to the context that it produces, so that, for instance, once we commit to computer technology, we are committed to particular limits. The juxtaposition of this Heidegerrian "enframing" (ge-stell) and computational theory as a symbolic process based upon a simple binary language demonstrates that this is not a world without limits, as Microsoft would have us believe, but rather a world of Windows NT's limits, of Intel's limits, of Apple's limits, and so on. Such is the context within which, once we have committed to IT, we must work in terms of establishing teaching and learning goals, student outcomes assessment and the like. Furthermore, Dewey's science-based educational model looked to active engagement as a cornerstone for the acquisition of knowledge [4]. Much of IT can be seen to follow such a pattern, and a Dewey-esque pragmatism makes an interrogative and dialogic framework essential to justifying IT in the classroom. Conceived of as a problem solving activity, learning can be fruitfully viewed as a question-asking activity, with its results seen as answers to "Why" questions such as "Why use HTML programming as opposed to Microsoft Front Page?" and "Why should I be moral?" Such a "discovery based" approach allows the student to learn subject matter, as well as gain valuable practice in higher-order problem solving skills [15].

Such considerations bring us face to face with the dichotomy between constructivist and more traditional (i.e., Socratic) pedagogy. Consider Jane Roland Martin's "The Two Dogmas of Curriculum" wherein she maintains that curricula are to be conceived not as static monoliths, but rather as dynamic systems of our own construction where disturbing any one strand will necessarily affect the other strands [11]. The process of education is, then, a constructivist process of continually asking questions of the belief system. In a sense, the Socratic system is no different. While Socrates is firmly committed to the notion that education is simply a process of recollecting the Forms (see Plato's discussion in Republic), education is still, nonetheless, contextual, as it were seeking answers from a set of pre-existing premises. Plato's cumbersome metaphysics aside, the critical factor for us to examine is the dynamic relationship between the learner, the teacher, and the belief systems that frame the pragmatic context of education. That both Dewey and Heidegger viewed technology in the traditional Greek sense of techné should not surprise us. Technology is itself a form of knowledge, and it embodies cultural assumptions and establishes novel educational contexts.

\section{Advantages of Using Instructional Technology}

Just as we have considered the theoretical underpinnings of IT, we must also discuss the practical uses of IT. The educational contexts developed from the use of technology know no limits in the classroom. Liaw offers five characteristics of web-based environments that are designed to enhance learning: Web-based systems offer a multi-media environment; integrate various kinds 
of information and construct information bases; support interactive communication; support networks to access information; and provide a cross-platform environment so regardless of the computer operating system students use, their information can be posted and accessed by others [10]. In addition to these benefits, activities associated with IT (e.g., e-mail assignments, bulletin boards, developing an outline for a project management course, and streaming video of famous speeches or other historical events) have the potential to revolutionize the classroom: students participate equally (numerous studies have shown that classroom discussion often favors males, but the relative anonymity of e-discussion allows for participation from all students); students learn both synchronously and asynchronously; faculty availability is increased; students and teachers are involved in global networks and joint projects with developing nations; students, who would otherwise be excluded, are allowed to obtain educational opportunities; and large numbers of students may be educated with relatively additional cost $[1,9,10,14,16]$. Yet, all students and faculty must possess the knowledge necessary to utilize IT as well as the means to access the technology. This disparity between those who do and do not have access to technology, often referred to as the "Digital Divide," has generated a lot of attention and, as a result, may possibly be reduced over time, thus demonstrating the cultural and economic reach of technology itself.

\section{Considerations for Using Instructional Technology}

With IT, we truly have the opportunity to develop "classrooms without walls." Yet, we must be mindful of the walls that we construct. Students can be given more autonomy to enter into and conduct dialogue with others but for some instructors, this means reconceptualizing their pedagogical approach. This newfound freedom might also be difficult for students to handle, as they may not have been granted this type of autonomy before. We must also be weary of the pitfalls of IT. Millions of dollars have been distributed to institutions for the sole purpose of "technology." Many times, it seems, without much thought given to technical responsibilities such as training, updating to new software packages, and how technology can best serve students. Instead, technology is often implemented for technology's sake.

As early as 1954, French sociologist Jacques Ellul warned in The Technological Society that technology had the capacity to become an end unto itself, that it was no longer a mere means to human-constructed ends, but that technology was itself its own reason for being [5]. Consider Pyle and Dziuban's observations that instructors who use IT are more excited by the vehicle than by what it communicates and that each new tool requires an investment in learning and time to assess its effectiveness - an assessment that rarely takes place [13]. We must remember that IT, like other tools, is a means to human-constructed ends and that once we allow the computerization of education to become an end unto itself, we are forever trapped within its own context and, as a result, will live within that context's consequences. For pedagogues, this may mean a situation where students are granted more autonomy and faculty have more opportunities to create a larger classroom context; however, this may also mean that students may rely more upon technological rather than interpersonal skills and that faculty may also come to rely on technology as the ultimate means to an educational end.

Indeed, instructors must consider the aims of IT used in their classrooms. As Newson so pointedly observes: 
Many technology enthusiasts, for example, seem to look on teaching and learning as narrowly technical processes, or as discrete activities that can be divorced from each other and rearranged to fit with the technical capabilities and operational requirements of the technology. [12]

Moreover, as soon as an instructor agrees to use an IT program within the classroom, that instructor and, by default, the students are forced to learn using the method embedded in the program. That is, most students and, unfortunately, instructors adopt IT without thinking critically about its construct. Does it matter that a particular program reifies and rewards linear thinking? Does it matter that a program automatically selects a color scheme, rather than allow students to make these decisions for themselves? Does it matter that a program, once endorsed by an instructor, is not questioned in the classroom? Of course, we argue that these questions do matter. In fact, these questions should be driving instructors using IT, rather than the novelty or excitement associated with IT.

In 1987, Chickering and Ehrmann developed Seven Principles for Good Practice in Undergraduate Education. It is significant to note that in 1996, they published an annotated version of these practices featuring ways to fully realize these principles while using new technologies [3]. We offer these updated principles to instructors to help guide their use of IT:

- Good practice encourages contacts between students and faculty.

Through e-mail, list servers, and chat rooms, IT lends itself easily to this principle by increasing not only the quantity, but also the quality of interaction between students and faculty.

- Good practice develops reciprocity and cooperation among students.

IT helps shape a constructivist classroom where students utilize collaborative learning and are able to communicate with each other and oftentimes are more honest in their peer-reviews using a written medium.

- Good practice uses active learning techniques.

As noted above, IT expects students to assume responsibility for their learning.

- Good practice gives prompt feedback.

With IT programs such as Blackboard or eCollege, students can access instructor feedback as soon as it is posted. Students may also feel more comfortable asking an instructor about their performance in a written medium as well.

- Good practice emphasizes time on task.

Not only can certain programs document student's time spent on task via threaded discussions and the like, IT can help to make studying more efficient by providing a myriad of information to the students' homes thereby reducing travel time and the like. 
- Good practice communicates high expectations.

Teaching courses entirely online necessitates that an instructor's expectations be clearly defined. With IT that allows for peer-review and all students having access to each other's coursework, high expectations may not only be communicated by instructors, but met by students who are aware that the entire class-not just the instructor-will view their work.

\section{- Good practice respects diverse talents and ways of learning.}

IT is ideally suited for this characteristic. Through IT, instructors can ask that students analyze, synthesize, and evaluate virtual or actual solutions. Students may also have more access to powerful visuals or better organized materials.

When followed, these practices are meant to help guide instructors in their use of technology. By considering each component as it relates to IT, instructors will be able to improve their teaching as well as student learning.

In order for instructors to use IT appropriately, they must not only critically consider the structure and implicit values of any IT program, but they must also consider their role within the classroom. We encourage instructors to eschew the role of trainer and embrace the role of educator. As Newson writes,

...we do not need to teach our students how to use these new technologies; they will learn without us, as they have learned how to ride bicycles, drive cars, and operate televisions and videocassette recorders. Instead, our students need to learn how to evaluate technology and its proper place in human affairs. And, most important, they must learn how to see technology as only one among many of the tools available for shaping their social, cultural, and political futures. [12]

By unquestioningly embracing IT, we are not instructing our students in how to effectively evaluate technology; conversely, we are reinforcing the message that using technology for technology's sake is a valid and meritorious approach.

\section{CONCLUSION}

As educators, if we are not critical of the types of IT we use in our classrooms, how can we expect our students to engage in critical thinking? If we act as mere trainers, teaching our students simply how to use technology, then we have failed. Perhaps, a reminder of what being an educator entails is needed. Gandz reminds us that

...education has much less to do with information gathering than with developing an individual's thinking and reasoning so that he or she can appraise that information, and separate the relevant from the irrelevant and the important from the trivial.... The real value of education is not in what one learns, but in how one develops. [7]

In our attempts to educate individuals, we often lose sight of the developmental process, especially when a new IT program is sure to catch students' attention and keep them interested in the course. By keeping our focus on the gathering of information, rather than the development of 
an individual, we are shirking our duties as educators. Unfortunately, most IT programming is designed with an emphasis on information gathering, thus it is our responsibility to acknowledge this to our students and develop assignments that transcend rudimentary applications.

While we recognize the advantages of IT and have found the principles of constructivist classrooms to be similar to the Socratic method, we caution those instructors who embrace IT without critically thinking about the impact of the implicit values contained within any program will have on their classrooms. We recommend that instructors consider the seven principles of good practice in undergraduate education when making decisions about using IT. Additionally, we strongly encourage instructors to recommit themselves to performing the role of educator, rather than that of trainer. One way to maintain the role of educator is by embracing Berge's conceptualization of technological minimalism: "the unapologetic use of minimum levels of technology, carefully chosen with precise attention to their advantages and limitations, in support of well-defined instructional objectives" [2]. For it is only by focusing on the entire process of learning, rather than the means of learning, that we are able to best serve the needs of our students.

\section{REFERENCES}

1. Benbunan-Fich, R. (2002). Improving education and training with IT. Communications of the ACM, 45, 94-99.

2. Berge, Z. L. (1998). Interaction in post-secondary web-based learning. Educational Technology, 39, 5-11.

3. Chickering, A. W., \& Ehrmann, S. C. (1996). Implementing the seven principles: Technology as lever. AAHE Bulletin, October, 3-6.

4. Dewey, J. (1916). Democracy and education. New York: The Macmillan Company.

5. Ellul, J. (1964). The technological society. New York: Random House.

6. Freire, P. (1970). Pedagogy of the oppressed. New York: The Continuum Publishing Company.

7. Gandz, J. (1997). The death of teaching: The rebirth of education. Ivey Business Quarterly, Autumn, 11-13.

8. Heidegger, M. (1977). The question concerning technology and other essays. New York: Harper and Row, p. 19.

9. Koprowski, G. (2000). Online learning: The competitive edge. Information Week, August, 124-128.

10. Liaw, S. (2004). Considerations for developing constructivist web-based learning. International Journal of Instructional Media, 31, 309-321.

11. Martin, J. R. (1982). The two dogmas of curriculum. Synthese, 51, 5-20.

12. Newson, J. (1999). Techno-pedagogy and disappearing context. Academe, 85, 52-55.

13. Pyle, R. C., \& Dziuban, C. D. (2001). Technology: Servant or master of the online teacher? Library Trends, 50, 130-144.

14. Schriver, R., \& Giles, S. (1999). Real ROI numbers. Training \& Development, Aug, 51-52.

15. Simonson, M., \& Thompson, A. (1994). Educational computing foundations. New York: Macmillan College Publishing.

16. Warner, J. (1999). Look, no classroom-BAE's virtual university. Flexible Working, July, 12-13. 